\title{
Biosynthesis of polyhydroxyalkanoates containing hydroxyl group from glycolate in Escherichia coli
}

\author{
Chayatip Insomphun', Shingo Kobayashi ${ }^{2}$, Tetsuya Fujiki ${ }^{2}$ and Keiji Numata ${ }^{*}$
}

\begin{abstract}
Polyhydroxyalkanoates (PHAs) containing hydroxyl groups in a side chain were produced in recombinant Escherichia coli JM109 using glycolate as the sole carbon source. The propionate-CoA transferase ( $p c t$ ) gene from Megasphaera elsdenii and the $\beta$-ketothiolase ( $b k t B$ ) gene and phaCAB operon from Ralstonia eutropha H16 were introduced into $E$. coli JM109. A novel monomer containing a hydroxyl group, dihydroxybutyrate (DHBA), was the expected product of the condensation of glycolyl-CoA and acetyl-CoA by BktB. The recombinant strain produced a PHA containing 1 mol\% DHBA. The incorporation of DHBA may have been restricted because the expression of phaAB1 competes for acetylCOA. The PHA containing DHBA units were evaluated regarding thermal properties, such as melting temperature, glass transition temperature and thermal degradation temperature. The current study demonstrates a potential use of PHA containing hydroxyl groups as renewable resources in biological materials.
\end{abstract}

Keywords: Polyhydroxyalkanoates, Hydroxyl group, Escherichia coli, Glycolate

\section{Introduction}

Polyhydroxyalkanoates (PHAs), which are one of biodegradable polyesters, are produced intracellularly by a wide variety of microorganisms from carbon and energy storage compounds under unbalanced growth conditions (Doi et al. 1995; Madison and Huisman 1999; Rehm 2007). Because of their biodegradability, biocompatibility, and thermoprocessability, PHAs have attracted much attention for applications in agriculture, medicine, packaging and the food industry (Chen 2009; Numata et al. 2009; Sudesh and Iwata 2008; Verlinden et al. 2007). Poly(3-hydroxybutyrate), $\mathrm{P}(3 \mathrm{HB})$, is the most abundant PHA in nature. However, the application of $\mathrm{P}(3 \mathrm{HB})$ is limited by its high crystallinity and brittle nature (Sudesh et al. 2000). A variety of PHAs containing 3-hydroxybutyrate (3HB) and a second monomer, such as 3-hydroxypropionate (3HP), 4-hydroxybutyrate (4HB), 5-hydroxyvalerate $(5 \mathrm{HV})$, and 3-hydroxyhexanoate

\footnotetext{
${ }^{*}$ Correspondence: keiji.numata@riken.jp

1 Enzyme Research Team, RIKEN Center for Sustainable Resource Science,

2-1 Hirosawa, Wako-shi, Saitama 351-0198, Japan

Full list of author information is available at the end of the article
}

(3HHx), have been produced to improve material properties (Budde et al. 2011; Chuah et al. 2013; Fukui et al. 2009; Saito et al. 1996). The mechanical and thermal properties of PHA relate to its monomer composition, which depends on the type of carbon source used, the available metabolic pathway for PHA biosynthesis, and the substrate specificity of PHA synthase (PhaC) and related enzymes (Lu et al. 2009; Numata et al. 2012; Steinbüchel and Valentin 1995; Yamashita et al. 2006). Among various PHAs, those containing functional groups, such as benzyl, hydroxyl and carboxyl groups, are more attractive because the functional group side chain can improve their physical properties (Hazer and Steinbüchel 2007). Moreover, some reactive functional groups in PHA may be further modified by chemicals to extend their applications.

PHA with pendant hydroxyl groups has been prepared by chemical modification of unsaturated PHAs using potassium permanganate or a borane-tetrahydrofuran complex (Lee et al. 2000; Renard et al. 2005). However, it is not easy to control the optical purity of these products. Recently, Martin et al. have constructed a metabolic pathway of dihydroxybutyrate (DHBA) biosynthesis in 
Escherichia coli by the introduction of the propionatecoenzymeA transferase gene $(p c t)$ from Megasphaera elsdenii, the $\beta$-ketothiolase gene $(b k t B)$ and 3-hydroxybutyryl-coenzymeA dehydrogenase gene (phaB) from Ralstonia eutropha $\mathrm{H} 16$, and the thioesterase (tesB) gene from $E$. coli MG1655 (Martin et al. 2013). Their results have indicated the possibility of incorporating a DHBA unit into PHA by using the $p c t, b k t B$ and $p h a B$ genes. We proposed a pathway for the production of PHA containing a DHBA monomer, as shown in Fig. 1. Therefore, in this study, we demonstrated the biosynthesis of PHA containing side chains with hydroxyl groups in E. coli JM109 by introducing $p c t$ from $M$. elsdenii and the $b k t B$ and $p h a C A B$ operons from $R$. eutropha H16. Furthermore, the thermal properties and stabilities of the PHA with hydroxyl groups were characterized to determine the effects of the side chains.

\section{Materials and methods}

\section{Bacterial strains and culture conditions}

The bacterial strains and plasmids used in this study are listed in Table 1. Escherichia coli strains were grown at 37 or $30{ }^{\circ} \mathrm{C}$ on a Luria-Bertani (LB) medium (Becton, Dickinson and Company, NJ, USA) containing tryptone $(10 \mathrm{~g} / \mathrm{L})$, yeast extract $(5 \mathrm{~g} / \mathrm{L})$ and $\mathrm{NaCl}(5 \mathrm{~g} / \mathrm{L})$, and $100 \mu \mathrm{g} / \mathrm{ml}$ kanamycin and $100 \mu \mathrm{g} / \mathrm{ml}$ ampicillin were added to the medium when necessary.

\section{Construction of plasmids and strains}

DNA manipulations were conducted according to standard procedures (Sambrook and Russell 2001). The sequences of the oligonucleotide primers used in this study are listed in Table 2. A synthetic pct gene from $\mathrm{Meg}$ asphaera elsdenii (DDBJ accession number: LC126829, 1554 bp) with codon optimization was synthesized by Operon Biotechnologies (Tokyo, Japan). The ribosome

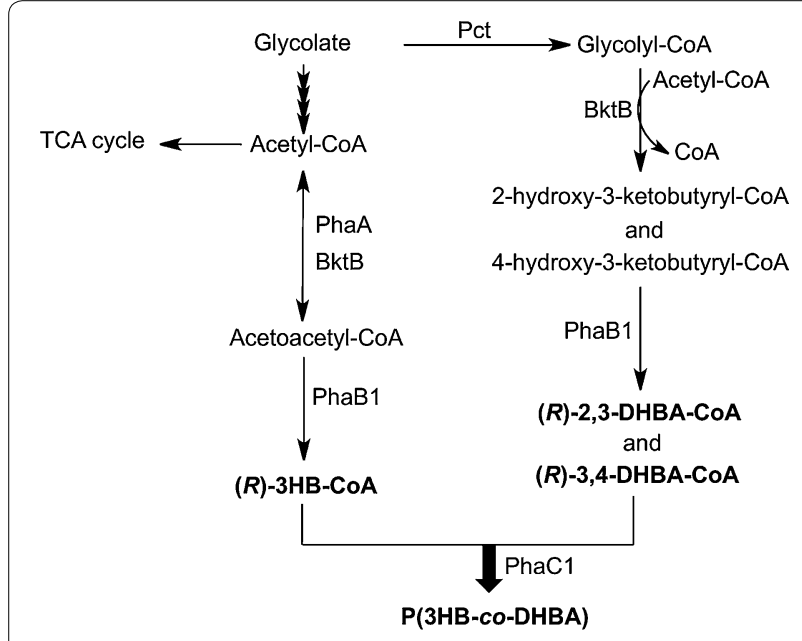

Fig. 1 Proposed biosynthesis pathway for the production of PHA containing a DHBA monomer in E. coli
Table 1 Bacterial strains and plasmids used in this study

\begin{tabular}{|c|c|c|}
\hline Strain or plasmid & Relevant marker & Source or reference \\
\hline \multicolumn{3}{|l|}{ Escherichia coli } \\
\hline JM109 & 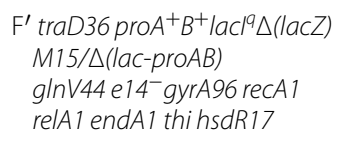 & Invitrogen \\
\hline \multicolumn{3}{|l|}{ Plasmids } \\
\hline $\mathrm{pBBR}-\mathrm{CAB}$ & $\begin{array}{l}\text { pBBR1-MCS2 derivative, } \\
\text { phaCAB }\end{array}$ & (Ushimaru et al. 2014) \\
\hline pTrcHis2B & pBR322 ori, $P_{\text {trc }}$ lac $1^{9}, \mathrm{Amp}^{r}$ & Invitrogen \\
\hline pTrc-pct & pTrcHis2B derivative, $p c t$ & This study \\
\hline pTrc-pct-bktB & $\begin{array}{l}\text { pTrcHis2B derivative, } p c t, \\
b k t B\end{array}$ & This study \\
\hline
\end{tabular}

Table 2 Sequences of the primers used in this study

\begin{tabular}{lll}
\hline Primer & Sequence $\left(\mathbf{5}^{\prime} \mathbf{-} \mathbf{3}^{\prime} \mathbf{)}\right.$ & Restriction site $^{\mathbf{a}}$ \\
\hline bktB-FwECoRI & CCGGAATTCAAGGAGGAATAAATGA & EcoRl \\
& CGCGTGAAGGGTAGTG & \\
bktB-RvXbal & TGCTCTAGAGCTCAGATACGCTCGA & Xbal \\
& AGATGGCG & \\
pct-FwBamHI & CGCGGATCCAATGCGCAAGGTGGAG & BamHI \\
& ATTATC & \\
pct-RvECoRI & CCGGAATTCTCACTTCTTCAGGCCCA & EcoRl \\
& TCGG & \\
\hline
\end{tabular}

${ }^{a}$ Indicated by underlining in the primer sequence

binding site and linker (AAAGGAGGAACAACC) were added, and the synthesized fragment was digested by EcoRI and BamHI and then inserted into the pBBR1MCS2 vector at the corresponding sites to obtain the pBBR-pct plasmid.

The pTrc-pct plasmid was constructed as follows. The pct gene was amplified with pBBR-pct and pctFwBamHI/pct-RvEcoRI as the template and primer, respectively. The amplified fragment was digested by $B a m \mathrm{HI}$ and EcoRI and then inserted into the pTrcHis2B vector at the corresponding sites to obtain the pTrc-pct plasmid. A coding region of $b k t B$ (H16_A1446, $1540 \mathrm{bp}$ ) was amplified by PCR with genomic DNA from $R$. eutropha $\mathrm{H} 16$ and bktB-FwEcoRI/bktB-RvXbaI as the template and primer, respectively. The amplified fragment was digested by EcoRI and XbaI and then inserted into the pTrc-pct vector at the corresponding sites to obtain the pTrc-pct-bktB plasmid.

pBBR-CAB was constructed as previously described (Ushimaru et al. 2014).

\section{Cultivation conditions}

PHA production by recombinant $E$. coli was conducted in $\mathrm{LB}$ medium at $37^{\circ} \mathrm{C}$ until an $\mathrm{OD}_{600}$ was reached 0.6. Then, PHA production was induced by adding a $1.0 \%$ 
$(w / v)$ filter-sterilized glucose solution or different concentrations of filter-sterilized solutions of sodium glycolate $[0.25,0.50,0.75$, and $1.0 \%(\mathrm{w} / \mathrm{v})]$ and isopropyl $\beta$-D-1-thiogalactopyranoside (IPTG) (final concentration of $1 \mathrm{mM}$ ), and the bacteria were cultured at $30^{\circ} \mathrm{C}$ for $72 \mathrm{~h}$. Then, the cells were harvested, washed three times with distilled water, and lyophilized.

\section{Enzyme assay}

Acetoacetyl-CoA, propionyl-CoA, and citrate synthase $(\geq 100$ units/mg protein) were purchased from Sigma Aldrich (Saint Louis, MO, USA). Recombinant E. coli was cultivated in $\mathrm{LB}$ medium at $37{ }^{\circ} \mathrm{C}$ until an $\mathrm{OD}_{600}$ was reached. IPTG was added to a final concentration of $1 \mathrm{mM}$, and cells continued to grow at $30{ }^{\circ} \mathrm{C}$ overnight. The cells were collected by centrifugation at $7500 \mathrm{rpm}$ for $10 \mathrm{~min}$, washed with $20 \mathrm{mM}$ Tris- $\mathrm{HCl}$ buffer, $\mathrm{pH} 7.4$, and resuspended in the same buffer (1 $\mathrm{g}$ of wet cell $/ 5 \mathrm{ml}$ buffer). The cells were disrupted by sonication (amplitude $=25$, process time $=5 \mathrm{~min}$, pulse on $=10 \mathrm{~s}$, and pulse off $=20 \mathrm{~s}$ ), and cell debris was removed by centrifugation $\left(12,000 \mathrm{rpm}, 4{ }^{\circ} \mathrm{C}\right.$, $10 \mathrm{~min}$ ) to obtain cell free extract. The activity of Pct was determined in the cell free extract by a spectroscopic assay (Lindenkamp et al. 2013). The $400 \mu \mathrm{l}$ reaction mixture contained $100 \mathrm{mM}$ Tris- $\mathrm{HCl}$ buffer, $\mathrm{pH}$ 7.4; $200 \mathrm{mM}$ sodium acetate; $20 \mathrm{mM}$ oxaloacetate; $2 \mathrm{mM}$ propionyl-CoA; $1 \mathrm{mM}$ 5,5'-dithiobis-(2-nitrobenzoic acid) (DTNB); 8 units of citrate synthase; and cell free extract. Absorbance was measured at $412 \mathrm{~nm}$. One unit was defined as the activity necessary to produce $1 \mu \mathrm{mol}$ of thionitrobenzoic acid (TNB) corresponding to the released free CoA-SH per minute $\left(\varepsilon_{412}=14,140 \mathrm{M}^{-1} \mathrm{~cm}^{-1}\right)$. $\beta$-ketothiolase was assayed in a $400 \mu \mathrm{l}$ reaction mixture containing $50 \mathrm{mM}$ Tris- $\mathrm{HCl}$ buffer, $\mathrm{pH}$ 7.4; $0.1 \mathrm{mM}$ acetoacetyl-CoA; $1 \mathrm{mM}$ coenzyme A trilithium salt; $25 \mathrm{mM} \mathrm{MgSO}_{4}$; and cell free extract. The decreased absorbance was measured at $304 \mathrm{~nm}$ (Mifune et al. 2010). One unit was defined as the activity necessary to produce $1 \mu \mathrm{mol}$ of $\mathrm{Mg}^{2+}$-3-ketoacyl-CoA complex per minute $\left(\varepsilon_{304}=19.5 \times 10^{3} \mathrm{M}^{-1} \mathrm{~cm}^{-1}\right)$.

\section{Polymer extraction from cells}

The polymer was extracted from the lyophilized cells by stirring the cells in chloroform for 3 days at room temperature. Cell debris was removed by filtration, and the polymer solution was purified by precipitation with tenfold volumes of hexane and methanol (Mifune et al. 2008). The purified polymer was vacuum dried before weighing.

\section{Polymer analyses}

PHA content within the cells was determined by gas chromatography-mass spectrometry (GC/MS) after ethanolysis of the dried cells with ethanol-chloroformhydrochloric acid at $100{ }^{\circ} \mathrm{C}$ for $4 \mathrm{~h}$, as described previously (Findlay and White 1983). Polymer composition was determined by ${ }^{1} \mathrm{H}$ nuclear magnetic resonance (NMR) spectra (VARIAN NMR System 500, Varian, Palo Alto, CA). The $500 \mathrm{MHz}{ }^{1} \mathrm{H}$ NMR spectra were recorded in a $\mathrm{CDCl}_{3}$ solution of PHA $(20 \mathrm{mg} / \mathrm{ml})$ at $27^{\circ} \mathrm{C}$.

The molecular weights of the polymers were obtained using gel-permeation chromatography (GPC) and a viscometer (Numata et al. 2005). GPC measurements were performed at $40{ }^{\circ} \mathrm{C}$ using a JASCO GPC system (RI2031, PU-2086, AS-202055, CO2056; JASCO, Tokyo, Japan) with a Shodex K-806 M, K802, and K-G column at $40{ }^{\circ} \mathrm{C}$. Chloroform was used as the mobile phase at a flow rate of $0.8 \mathrm{ml} / \mathrm{min}$, and the sample concentration used was approximately $1 \mathrm{mg} / \mathrm{ml}$. The calibration curve used for estimating the molecular weight was generated using polystyrene standards with low polydispersity. The molecular weights of the nine polystyrene standards were 3148843, 1074876, 460595, 156528, 66001, 28517, 10112, 3252 , and $1319 \mathrm{~g} / \mathrm{mol}$.

To determine the molecular weight by viscometry, viscosity was measured at $30{ }^{\circ} \mathrm{C}$ using a capillary glass Ubbelohde (SU 026130-0003, SIBATA) with a thermostat water bath (VB-3T, SIBATA, Saitama, Japan). For measurement, $13 \mathrm{ml}$ of solution was transferred into the Ubbelohde and incubated in the thermostat water bath for $15 \mathrm{~min}$. The flow time of the PHA solution was determined as the mean of three measurements. To obtain intrinsic viscosity, four PHA concentrations were measured. Sample concentrations varied within 100-175 mg of PHA per $100 \mathrm{ml}$ of chloroform. Molecular weights were calculated from the Mark-Houwink-Coon equation.

Differential scanning calorimetry (DSC) data were recorded at temperatures ranging from -50 to $200{ }^{\circ} \mathrm{C}$ on a Perkin-Elmer DSC 8500 instrument (Perkin-Elmer, Waltham, MA) equipped with a cooling accessory under a nitrogen flow rate of $20 \mathrm{ml} / \mathrm{min}$. The melt-crystallized films (approximately $3 \mathrm{mg}$ ) were encapsulated in aluminum pans and heated to $200{ }^{\circ} \mathrm{C}$ at $20^{\circ} \mathrm{C} / \mathrm{min}$, according to a previous report (Numata et al. 2004). The melting temperature $\left(T_{m}\right)$ and enthalpy of fusion $\left(\Delta H_{m}\right)$ were determined from the DSC endotherms. The glass transition temperature $\left(T_{m}\right)$, which was analyzed based on the DSC curves from the second heating, was taken as the midpoint of the heat capacity change.

The thermal degradation temperature of PHA was determined by thermogravimetric analysis (TGA) using 
a TGA/DSC2 STAR ${ }^{\mathrm{e}}$ system (Mettler Toledo, Switzerland). PHA (approximately $3 \mathrm{mg}$ ) was encapsulated in aluminum pans and heated from 30 to $400{ }^{\circ} \mathrm{C}$ at a heating rate of $20^{\circ} \mathrm{C} / \mathrm{min}$ under a nitrogen atmosphere.

\section{Results}

\section{Construction of the recombinant strain}

The PHA biosynthesis pathway in E. coli JM109 was constructed by introducing the plasmid containing the phaCAB operon from $R$. eutropha H16. DHBA units were generated by co-expressing the propionate-coenzyme A transferase gene ( $p c t)$ from $M$. elsdenii and the $\beta$-ketothiolase gene (bktB) from R. eutropha H16. The first step of this pathway is the formation of glycolyl-CoA from glycolate by Pct. Glycolyl-CoA is condensed with acetyl-CoA to form 2-Hydroxy-3-ketobutyryl-CoA and 4-Hydroxy-3-ketobutyryl-CoA by BktB (Fig. 1). The two intermediates are reduced to 3,4-dihydroxybutyryl-CoA (3,4-DHBA) and 2,3-dihydroxybutyryl-CoA (2,3-DHBA), respectively, by 3-hydroxybutyryl-CoA dehydrogenase (PhaB1). Finally, 3,4-DHBA and 2,3-DHBA are polymerized with 3-hydroxybutyryl-CoA (3HB-CoA) by PHA synthase1 (PhaC1).

The enzymatic activity of Pct and $\beta$-ketothiolase in the recombinant $E$. coli JM109 was determined by spectroscopic assay to confirm gene expression. Our results showed that the cell-free extract from recombinant $E$. coli JM109 harboring pBBR-CAB and pTrc-pct-bktB exhibited both Pct and $\beta$-ketothiolase activity. The specific activities of Pct and $\beta$-ketothiolase were 7.2 and $4.2 \mathrm{U} /$ $\mathrm{mg}$, respectively. The activity of the blank, containing no Pct or $\beta$-ketothiolase, was subtracted from each sample as background. These results confirmed that the $p c t$ and $b k t B$ genes were successfully expressed in E. coli JM109.

\section{Biosynthesis of PHA in recombinant E. coli JM109}

Recombinant E. coli JM109 was cultured in LB medium supplemented with $1 \%(\mathrm{w} / \mathrm{v})$ glucose or various concentrations of glycolate. The PHA contents were determined by GC/MS (Table 3), and the PHA content of the recombinant strain grown in glucose was approximately $6 \mathrm{wt} \%$. However, the PHA contents of the recombinant

Table 3 Biosynthesis of PHA in recombinant E. coli JM109 using glucose and glycolate as the sole carbon sources

\begin{tabular}{lll}
\hline Carbon sources $[\%(w / v)]$ & CDW $(\mathbf{g} / \mathbf{L})$ & PHA content $(\mathbf{w t} \%)$ \\
\hline $1.0 \%$ glucose & $0.67 \pm 0.03$ & $5.5 \pm 0.5$ \\
$0.25 \%$ glycolate & $0.31 \pm 0.10$ & $0.9 \pm 0.3$ \\
$0.50 \%$ glycolate & $0.47 \pm 0.01$ & $0.9 \pm 0.2$ \\
$0.75 \%$ glycolate & $0.42 \pm 0.02$ & $0.7 \pm 0.1$ \\
$1.0 \%$ glycolate & $0.39 \pm 0.01$ & $0.7 \pm 0.03$
\end{tabular}

E. coli JM109 were relatively low $(<1 \mathrm{wt} \%)$ for all glycolate concentrations used. Cell growth and PHA content decreased when the cells were grown with 0.75 and $1.0 \%$ $(w / v)$ glycolate. This result indicated that high concentrations of glycolate had an inhibitory effect on cell growth and PHA production. Therefore, $0.5 \%(\mathrm{w} / \mathrm{v})$ glycolate was selected for further polymer production.

\section{Characterization of PHA}

The composition of the extracted polymer was investigated with ${ }^{1} \mathrm{H}$ NMR and $2 \mathrm{D}\left({ }^{1} \mathrm{H}-{ }^{1} \mathrm{H}\right)$ COSY NMR spectroscopy, which revealed that in addition to $3 \mathrm{HB}$ units, $3 \mathrm{HV}$ units and novel monomers containing side chains with hydroxyl groups and 2,3-DHBA were incorporated into PHA. The mole fraction of the 3HV and 2,3-DHBA monomers was $1 \mathrm{~mol} \%$. The completed assignments of the ${ }^{1} \mathrm{H}-\mathrm{NMR}$ spectra in $\mathrm{CDCl}_{3}$ are shown in Fig. 2a. The methyl protons of $3 \mathrm{HV}$ were assigned at $\delta 0.7-0.8 \mathrm{ppm}$. The methyl protons of 2,3-DHBA and $3 \mathrm{HB}$ were assigned at the regions of $\delta 1.1-1.4 \mathrm{ppm}$. The methylene protons of $3 \mathrm{HV}$ were assigned at $\delta 1.7-1.8 \mathrm{ppm}$. The methylene protons of 2,3-DHBA and $3 \mathrm{HB}$ were assigned at $\delta 2.4-2.8 \mathrm{ppm}$. The oxymethine proton connected to the hydroxyl group was assigned at the region of $\delta 4.3-$ $4.4 \mathrm{ppm}$. The oxymethine protons of $3 \mathrm{HB}$ and $3 \mathrm{HV}$ were around $\delta 5.2-5.9 \mathrm{ppm}$.

Figure $2 \mathrm{~b}$ shows the COSY spectrum. The signal (1) between the methine proton connected to the hydroxyl group of 2,3-DHBA and the oxymethine proton of 2,3DHBA appeared at $\delta 4.3 / 2.6 \mathrm{ppm}$. The coupling (2) between the oxymethine proton of 2,3-DHBA and the methyl protons of 2,3-DHBA was seen at $\delta 2.6 / 1.3 \mathrm{ppm}$. The coupling (3) between the oxymethine proton of $3 \mathrm{HB}$ and the methylene protons of $3 \mathrm{HB}$ was assigned at $\delta 5.3 / 2.6 \mathrm{ppm}$, whereas the coupling (4) between the oxymethine proton of $3 \mathrm{HB}$ and the methyl protons of $3 \mathrm{HB}$ appeared at $\delta 5.3 / 1.3 \mathrm{ppm}$. The coupling (5) between the methylene protons of $3 \mathrm{HV}$ and the methyl protons of $3 \mathrm{HV}$ was seen at $\delta 1.6 / 0.9 \mathrm{ppm}$.

It has been reported that the molecular weight of PHA can be affected by PHA synthase activity, the type and concentration of carbon source (Sim et al. 1997; Taidi et al. 1994). The recombinant $E$. coli JM109 produced a polymer with a number-average molecular weight $\left(M_{n}\right)$ of $0.5 \times 10^{6} \mathrm{~g} / \mathrm{mol}$ and polydispersity index (PDI) of 3.2 from glycolate.

\section{Thermal analysis}

Incorporation of $3 \mathrm{HV}$ and 2,3-DHBA monomers into $\mathrm{P}(3 \mathrm{HB})$ had an effect on its thermal properties (Table 4). The $T_{m}, \Delta H_{m}$, and $T_{g}$ values were lower than those of the $\mathrm{P}(3 \mathrm{HB})$ homopolymer. However, the $\Delta H_{m}$ value was higher than that of $\mathrm{P}(3 \mathrm{HB}-c o-2 \mathrm{~mol} \% 3 \mathrm{HV})$. The increase 
a

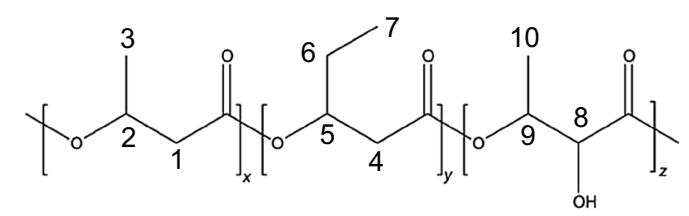

$1,4,9$
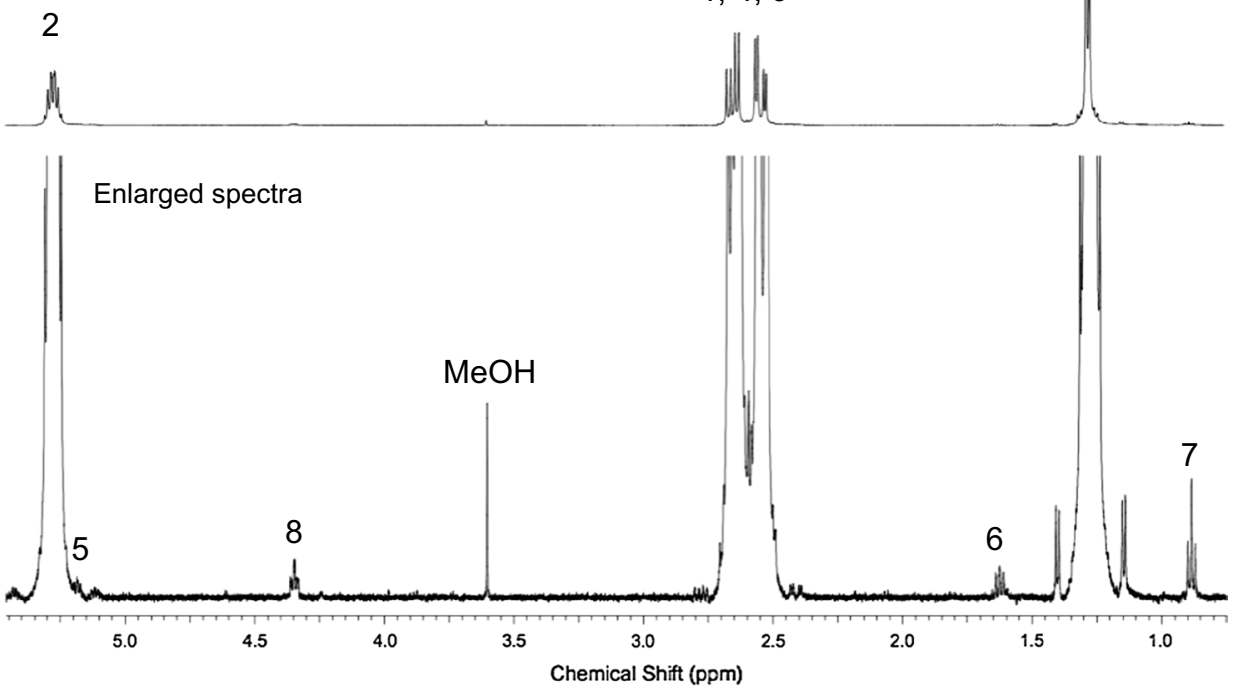

b

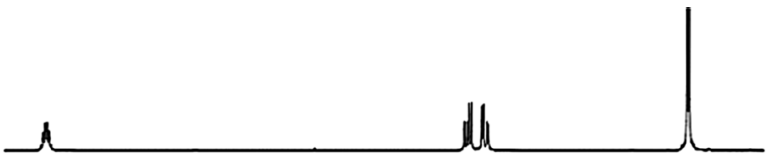

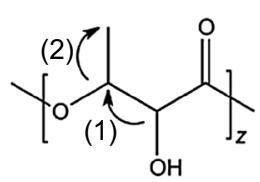

\section{2,3-DHBA}

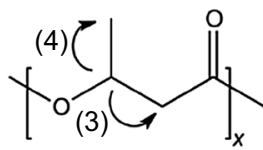
3HB<smiles>CCC(CC(C)=O)OC(C)(C)C</smiles>

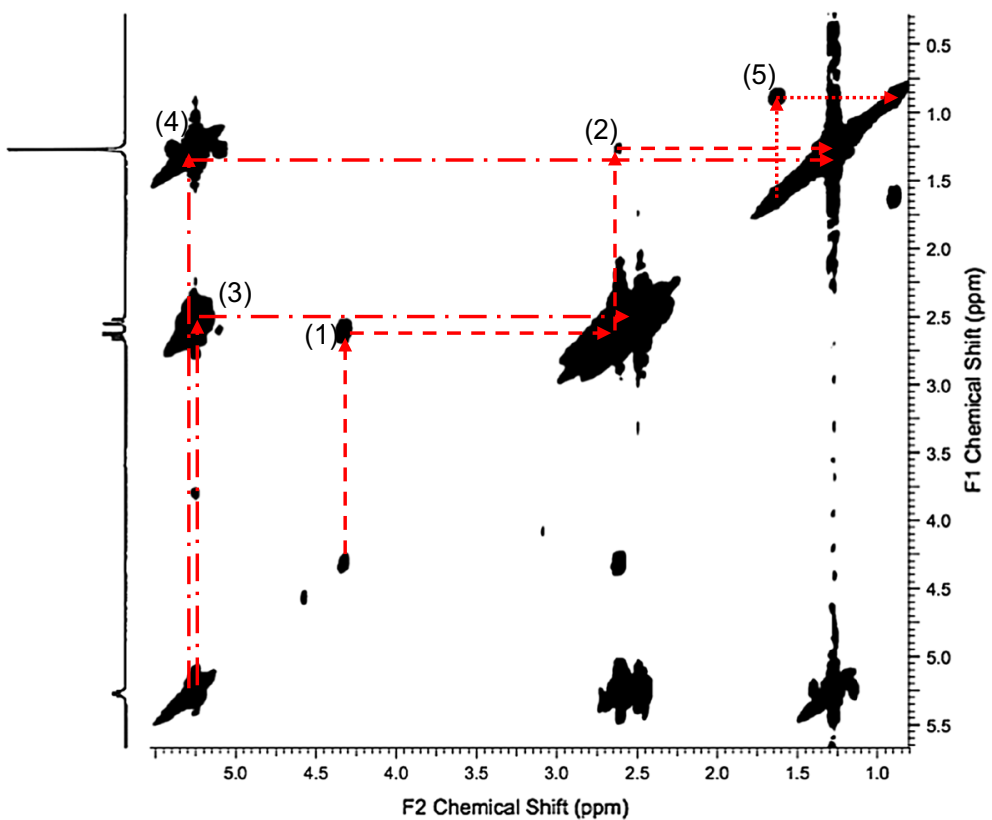

Fig. 2 NMR analysis of P(3HB-co-1 mol\% 3HV-co-1 mol\% 3,4-DHBA) produced in E. coli JM109 harboring pBBR-CAB and pTrc-pct-bktB. a 500 MHz ${ }^{1} \mathrm{H}$ NMR spectra and $\mathbf{b}^{1} \mathrm{H}^{1}{ }^{1} \mathrm{H}$ COSY spectra 
Table 4 Thermal properties of $\mathrm{P}(3 \mathrm{HB}), \mathrm{P}(3 \mathrm{HB}-\mathrm{co}-3 \mathrm{HV})$ and P(3HB-CO-DHBA)

\begin{tabular}{lrrl}
\hline Samples & $\boldsymbol{T}_{\boldsymbol{g}}\left({ }^{\circ} \mathbf{C}\right)$ & $\boldsymbol{T}_{\boldsymbol{m}}\left({ }^{\circ} \mathbf{C}\right)$ & $\boldsymbol{\Delta H}_{\boldsymbol{m}}\left(\mathbf{J g}^{\mathbf{- 1}}\right)$ \\
\hline P(3HB) (Shimamura et al. 1994) & 4.0 & 177.0 & 97.0 \\
P(3HB-CO-2 mol\% 3HV) (Lee et al. 2008) & -0.7 & 168.0 & 65.2 \\
P(3HB-CO-1 mol\% 3HV-co-1 mol\%-2,3- & 0.1 & 168.8 & 90.3 \\
DHBA) & & & \\
\hline
\end{tabular}

in $\Delta H_{m}$ may be due to the incorporation of 2,3-DHBA and its effects on the nucleation of crystallinity.

To investigate the thermal degradation behavior of P(3HB-co-1 mol\% 3HV-co-1 mol\%-2,3-DHBA), TGA was used. Figure 3 shows the TGA curves with a heating rate of $20{ }^{\circ} \mathrm{C} / \mathrm{min}$. The TGA curves decreased with temperature due to the thermal degradation of PHA, and there was no char left from $\mathrm{P}(3 \mathrm{HB})$. The thermal degradation temperatures of 1,5 and $10 \mathrm{wt} \%$ weight loss $\left(T_{1 \%}\right.$, $T_{5} \%$ and $T_{10} \%$ for $\mathrm{P}(3 \mathrm{HB})$ and $\mathrm{P}(3 \mathrm{HB}-\mathrm{co}-1 \mathrm{~mol} \% 3 \mathrm{HV}-$ co-1 mol\%-2,3-DHBA) are listed in Table 5. The thermal decomposition for $\mathrm{P}(3 \mathrm{HB}-\mathrm{co}-1 \mathrm{~mol} \% 3 \mathrm{HV}-\mathrm{co}-1 \mathrm{~mol} \%$ 2,3-DHBA) at 1,5 , and $10 \%$ weight loss was higher than that for $\mathrm{P}(3 \mathrm{HB})$.

\section{Discussion}

PHAs have attracted attention as an alternative to petroleum-based plastic because of their reproducibility from renewable resources. PHAs also show potential in a wide range of applications due to their biodegradability, biocompatibility, and thermoprocessability. To extend their properties and applications, PHAs containing functional groups have been synthesized using several types of microorganisms. Pseudomonas species have

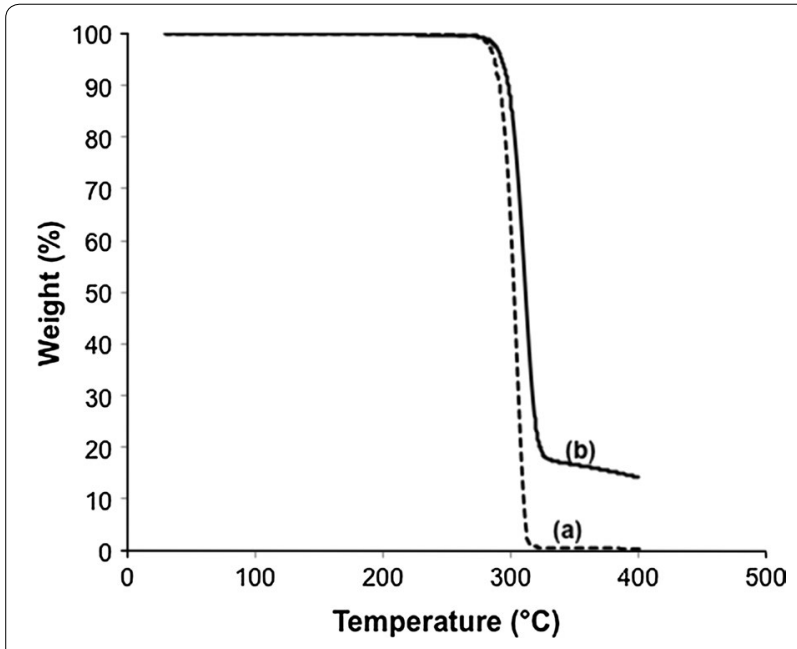

Fig. 3 TGA curve of PHA samples. a P(3HB) and b P(3HB-co-1 mol\% 3HV-co-1 mol\% 3,4-DHBA)
Table 5 Thermal degradation temperatures of PHA samples

\begin{tabular}{llll}
\hline Samples & $\boldsymbol{T}_{\mathbf{1} \%}\left({ }^{\circ} \mathbf{C}\right)$ & $\boldsymbol{T}_{\mathbf{5} \%}\left({ }^{\circ} \mathbf{C}\right)$ & $\boldsymbol{T}_{\mathbf{1 0} \%}\left({ }^{\circ} \mathbf{C}\right)$ \\
\hline $\mathrm{P}(3 \mathrm{HB})$ & 277.7 & 287.0 & 290.9 \\
$\mathrm{P}(3 \mathrm{HB}-\mathrm{CO}-1 \mathrm{~mol} \%$ 3HV-CO- & 280.7 & 293.0 & 297.7 \\
1 mol\%-2,3-DHBA) & & & \\
\hline
\end{tabular}

been reported to biosynthesize medium-chain-length PHAs containing various functional groups at the terminal position in the presence of carbon sources containing these functional groups (Kim et al. 2000; Lenz et al. 1992). In addition, PHAs with pendant functional groups have been obtained by chemical modification of PHA with unsaturated side chains (Hany et al. 2004; Park et al. 1998). Recently, dihydroxybutyrates (DHBAs) have been produced in E. coli expressing the pct, phaB, and tesB genes grown on glucose supplemented with glycolate (Martin et al. 2013). The chemical structure of DHBA is similar to $3 \mathrm{HB}$, which is the most abundant component of PHA in nature, with an additional hydroxyl group. Therefore, modifying a pathway for the biosynthesis of PHA containing DHBA monomers may be useful for producing a novel PHA with pendant hydroxyl groups.

In this study, an artificial pathway for the generation of DHBA-CoA from glycolate was constructed by introducing pct from $M$. elsdenii and $b k t B$ from $R$. eutropha H16 into $E$. coli JM109. The phaCAB operon from $R$. eutropha $\mathrm{H} 16$ was also introduced to generate the PHA biosynthesis pathway. Then, PHA biosynthesis was conducted using glycolate as the sole carbon source. Based on the current results, the PHA content was relatively low $(<1 \mathrm{wt} \%)$ compared with the samples using glucose as a carbon source (5.5 wt\%). In PHA biosynthesis pathway, provision of hydroxyalkanoate monomers is supplied in the cells via metabolism of carbon sources. The type of carbon source used for cultivation effects on PHA production. Therefore, the low PHA content was likely due to the pathway for supplying PHA biosynthesis competes for glycolate metabolism (Hansen and Hayashi 1962). NMR analyses revealed that a small fraction of 2,3-DHBA (1 mol\%) was incorporated into PHA. In a previous report, the recombinant strains has been found to produce both 3,4-DHBA and 2,3-DHBA in similar ratios (Martin et al. 2013). This report indicates that 3,4-DHBA-CoA is not a favorable substrate for PHA synthase compared with 2,3DHBA. The low composition of DHBA was likely due to high metabolic flux of $(R)$-3HB-CoA, the most preferred substrate for PHA synthase, owing to the expression of the $R$. eutropha phaAB1 genes. It has been reported that efficient PHA production can be achieved by enhancing metabolic flux to supply intermediates sufficient for PHA biosynthesis and by expressing PHA synthase that 
has high substrate specificity toward the desired monomer (Fukui et al. 1999; Park et al. 2012). We therefore developed strategies for supplying more DHBA monomers from glycolate and improving substrate specificity toward DHBA-CoA. It is possible to decrease the carbon flux from glycolate to acetyl-CoA by disrupting the glycolate oxidase gene, which catalyzes the first reaction, in which glycolate is converted to glyoxylate. Furthermore, the application of another PHA synthase may improve the incorporation of DHBA monomers into PHA. These strategies will be investigated in the future.

The number-average molecular weight $\left(M_{n}\right)$ of the polymer in the present study was lower than that synthesized by recombinant $E$. coli TOP10 using glucose $\left(M_{n}=2.5 \times 10^{6} \mathrm{~g} / \mathrm{mol}\right.$ and PDI $\left.=1.6\right)$ (Ushimaru et al. 2014). The decrease in molecular weight and broader molecular weight distribution may be due to interference with the polymerization reaction of PHA synthase by the incorporation of $3 \mathrm{HV}$ and 2,3-DHBA monomers into PHA. In addition, the unusual carbon source also resulted in a decreased polymer molecular weight.

The melting and glass transition temperatures of the polymer did not significantly differ from those of $\mathrm{P}(3 \mathrm{HB})$, even with the low composition of the DHBA monomer units. Both of these thermal decomposition processes depended on the monomer composition. Our results indicated that the thermal decomposition temperature of $\mathrm{P}(3 \mathrm{HB}-\mathrm{co}-1 \mathrm{~mol} \% 3 \mathrm{HV}-\mathrm{co}-1 \mathrm{~mol} \%-2,3-\mathrm{DHBA})$ was higher than that of $\mathrm{P}(3 \mathrm{HB})$ (Table 5); hence, incorporation of 2,3-DHBA affects the thermal degradation process of PHA. However, Lee et al. have reported that high contents of hydroxyl groups reduces the thermal stability of PHA (Lee et al. 2001). The hydroxyl groups are able to react with the ester linkages in the main chain, resulting in molecular weight loss and volatilization. Therefore, the appropriate DHBA composition in PHA should be adjusted for the practical application of this polymer.

In conclusion, this is the first report of the microbial production of $\mathrm{P}(3 \mathrm{HB}-\mathrm{co}-3 \mathrm{HV}-\mathrm{co}-2,3-\mathrm{DHBA})$ from glycolate. We constructed an artificial pathway that generated DHBA-CoA by introducing the pct gene from $M$. elsdenii and the bktB gene from $R$. eutropha H16 into E. coli JM109. The PHA production was approximately $1 \mathrm{wt} \%$ of the dry cell weight, and the DHBA composition was approximately $1 \mathrm{~mol} \%$. Further metabolic engineering to supply more DHBA monomers and improve PHA production will be developed in future studies. The thermal properties of PHAs containing DHBA were also characterized, thus providing valuable information for designing new types of PHAs. This study provides new insights into synthesizing PHA containing hydroxyl groups from renewable resources via designed metabolic pathways.

\section{Author details}

${ }^{1}$ Enzyme Research Team, RIKEN Center for Sustainable Resource Science, 2-1 Hirosawa, Wako-shi, Saitama 351-0198, Japan. ${ }^{2}$ Kaneka Corporation, 1-8 Miyamae-cho, Takasago-cho, Takasago, Hyogo 676-8688, Japan.

\section{Acknowledgements}

We thank Dr. Kenjiro Yazawa for his help with thermal analysis.

This article does not contain any studies with human participants or animals performed by any of the authors.

\section{Competing interests}

The authors declare that they have no competing interests.

\section{Funding}

This study was financially supported by RIKEN Biomass Engineering Program.

Received: 29 March 2016 Accepted: 6 April 2016

Published online: 14 April 2016

\section{References}

Budde CF, Riedel SL, Willis LB, Rha C, Sinskey AJ. Production of poly(3-hydroxybutyrate-co-3-hydroxyhexanoate) from plant oil by engineered Ralstonia eutropha strains. Appl Environ Microbiol. 2011;77:2847-54.

Chen GQ. A microbial polyhydroxyalkanoates (PHA) based bio- and materials industry. Chem Soc Rev. 2009;38:2434-46.

Chuah J-A, Yamada M, Taguchi S, Sudesh K, Doi Y, Numata K. Biosynthesis and characterization of polyhydroxyalkanoate containing 5-hydroxyvalerate units: effects of $5 \mathrm{HV}$ units on biodegradability, cytotoxicity, mechanical and thermal properties. Poly Degrad Stab. 2013;98:331-8.

Doi Y, Kitamura S, Abe H. Microbial synthesis and characterization of poly(3-hydroxybutyrate-co-3-hydroxyhexanoate). Macromolecules. 1995;28:4822-8.

Findlay RH. White DC polymeric beta-hydroxyalkanoates from environmental samples and Bacillus megaterium. Appl Environ Microbiol. 1983;45:71-8.

Fukui T, Suzuki M, Tsuge T, Nakamura S. Microbial synthesis of poly((R)-3-hydroxybutyrate-co-3-hydroxypropionate) from unrelated carbon sources by engineered Cupriavidus necator. Biomacromolecules. 2009;10:700-6.

Fukui T, Yokomizo S, Kobayashi G, Doi Y. Co-expression of polyhydroxyalkanoate synthase and (R)-enoyl-CoA hydratase genes of Aeromonas caviae establishes copolyester biosynthesis pathway in Escherichia coli. FEMS Microbiol Lett. 1999;170:69-75.

Hansen RW, Hayashi JA. Glycolate metabolism in Escherichia coli. J Bacteriol. 1962;83:679-87.

Hany R, Böhlen C, Geiger T, Hartmann R, Kawada J, Schmid M, Zinn M, Marchessault RH. Chemical synthesis of crystalline comb polymers from olefinic medium-chain-length poly[3-hydroxyalkanoates]. Macromolecules. 2004;37:385-9.

Hazer B, Steinbüchel A. Increased diversification of polyhydroxyalkanoates by modification reactions for industrial and medical applications. Appl Microbiol Biotechnol. 2007;74:1-12.

Kim DY, Kim YB, Rhee YH. Evaluation of various carbon substrates for the biosynthesis of polyhydroxyalkanoates bearing functional groups by Pseudomonas putida. Int J Biol Macromol. 2000;28:23-9.

Lee MY, Lee TS, ParkWH. Effect of side chains on the thermal degradation of poly(3-hydroxyalkanoates). Macromol Chem Physic. 2001;202:1257-61.

Lee MY, Park WH, Lenz RW. Hydrophilic bacterial polyesters modified with pendant hydroxyl groups. Polymer. 2000;41:1703-9.

Lee W-H, Loo C-Y, Nomura CT, Sudesh K. Biosynthesis of polyhydroxyalkanoate copolymers from mixtures of plant oils and 3-hydroxyvalerate precursors. Bioresour Tech. 2008:99:6844-51.

Lenz RW, Kim YB, Fuller RC. Production of unusual bacterial polyesters by Pseudomonas oleovorans through cometabolism. FEMS Microbiol Lett. 1992;103:207-14.

Lindenkamp N, Schürmann M, Steinbüchel A. A propionate CoA-transferase of Ralstonia eutropha $\mathrm{H} 16$ with broad substrate specificity catalyzing the CoA thioester formation of various carboxylic acids. Appl Microbiol Biotechnol. 2013;97:7699-709. 
Lu JN, Tappel RC, Nomura CT. Mini-review: biosynthesis of poly(hydroxyalkanoates). Polym Rev. 2009;49:226-48.

Madison LL, Huisman GW. Metabolic engineering of poly(3-hydroxyalkanoates): from DNA to plastic. Microbiol Mol Biol Rev. 1999;63:21-53.

Martin CH, Dhamankar H, Tseng HC, Sheppard MJ, Reisch CR, Prather KL. A platform pathway for production of 3-hydroxyacids provides a biosynthetic route to 3-hydroxy-gamma-butyrolactone. Nat Commun. 2013;4:1414.

Mifune J, Nakamura S, Fukui T. Targeted engineering of Cupriavidus necator chromosome for biosynthesis of poly(3-hydroxybutyrate-co-3-hydroxyhexanoate) from vegetable oil. Can J Chem. 2008;86:621-7.

Mifune J, Nakamura S, Fukui T. Engineering of pha operon on Cupriavidus necator chromosome for efficient biosynthesis of poly(3-hydroxybutyrate-co-3-hydroxyhexanoate) from vegetable oil. Polym Degrad Stab. 2010;95:1305-12.

Numata K, Abe H, Iwata T. Biodegradability of poly(hydroxyalkanoate) materials. Materials. 2009;2:1104-26.

Numata K, Hirota T, Kikkawa Y, Tsuge T, Iwata T, Abe H, Doi Y. Enzymatic degradation processes of lamellar crystals in thin films for poly $[(R)-3-h y-$ droxybutyric acid] and its copolymers revealed by real-time atomic force microscopy. Biomacromolecules. 2004;5:2186-94.

Numata K, Kikkawa Y, Tsuge T, Iwata T, Doi Y, Abe H. Enzymatic degradation processes of poly[(R)-3-hydroxybutyric acid] and poly[(R)-3-hydroxybutyric acid-co-(R)-3-hydroxyvaleric acid] single crystals revealed by atomic force microscopy: effects of molecular weight and second-monomer composition on erosion rates. Biomacromolecules. 2005:6:2008-16.

Numata K, Motoda Y, Watanabe S, Tochio N, Kigawa T, Doi Y. Active intermediates of polyhydroxyalkanoate synthase from Aeromonas caviae in polymerization reaction. Biomacromolecules. 2012;13:3450-5.

Park S, Lee T, Lim S-C, Kim T, Lee H, Kim M, Lee S, Song B, Lee S. Biosynthesis of polyhydroxyalkanoates containing 2-hydroxybutyrate from unrelated carbon source by metabolically engineered Escherichia coli. Appl Microbiol Biotechnol. 2012:93:273-83.

Park WH, Lenz RW, Goodwin S. Epoxidation of bacterial polyesters with unsaturated side chains. I. production and epoxidation of polyesters from 10-undecenoic acid. Macromolecules. 1998;31:1480-6.

Rehm BH. Biogenesis of microbial polyhydroxyalkanoate granules: a platform technology for the production of tailor-made bioparticles. Curr Issues Mol Biol. 2007;9:41-62.
Renard E, Poux A, Timbart L, Langlois V, Guérin P. Preparation of a novel artificial bacterial polyester modified with pendant hydroxyl groups. Biomacromolecules. 2005:6:891-6.

Saito Y, Nakamura S, Hiramitsu M, Doi Y. Microbial synthesis and properties of poly(3-hydroxybutyrate-co-4-hydroxybutyrate). Polym Int. 1996;39:169-74.

Sambrook J, Russell DW. Molecular cloning: Q laboratory manual. 3rd ed. New York: Cold Spring Harbor Laboratory; 2001

Shimamura E, Scandola M, Doi Y. Microbial Synthesis and Characterization of Poly(3-hydroxybutyrate-co-3-hydroxypropionate). Macromolecules. 1994:27:4429-35.

Sim SJ, Snell KD, Hogan SA, Stubbe J, Rha C, Sinskey AJ. PHA synthase activity controls the molecular weight and polydispersity of polyhydroxybutyrate in vivo. Nat Biotech. 1997;15:63-7.

Steinbüchel A, Valentin HE. Diversity of bacterial polyhydroxyalkanoic acids. FEMS Microbiol Lett. 1995;128:219-28.

Sudesh K, Abe H, Doi Y. Synthesis, structure and properties of polyhydroxyalkanoates: biological polyesters. Prog Polym Sci. 2000;25:1503-55.

Sudesh K, Iwata T. Sustainability of biobased and biodegradable plastics. CLEAN Soil Air Water. 2008:36:433-42.

Taidi B, Anderson A, Dawes E, Byrom D. Effect of carbon source and concentration on the molecular mass of poly(3-hydroxybutyrate) produced by Methylobacterium extorquens and Alcaligenes eutrophus. Appl Microbiol Biotechnol. 1994;40:786-90.

Ushimaru K, Motoda Y, Numata K, Tsuge T. Phasin proteins activate Aeromonas caviae polyhydroxyalkanoate (PHA) synthase but not Ralstonia eutropha PHA synthase. Appl Environ Microbiol. 2014;80:2867-73.

Verlinden RAJ, Hill DJ, Kenward MA, Williams CD, Radecka I. Bacterial synthesis of biodegradable polyhydroxyalkanoates. J Appl Microbiol. 2007; 102:1437-49.

Yamashita K, Yamada M, Numata K, Taguchi S. Nonspecific hydrophobic interactions of a repressor protein, PhaR, with poly[(R)-3-hydroxybutyrate] film studied with a quartz crystal microbalance. Biomacromolecules. 2006;7:2449-54.

\section{Submit your manuscript to a SpringerOpen ${ }^{\odot}$ journal and benefit from:}

- Convenient online submission

- Rigorous peer review

- Immediate publication on acceptance

- Open access: articles freely available online

- High visibility within the field

- Retaining the copyright to your article

Submit your next manuscript at springeropen.com 